\title{
Homosexual prostitution among male drug users and its risk for HIV infection
}

\author{
J A R van den Hoek, H J A van Haastrecht, R A Coutinho
}

\begin{abstract}
Objective-to assess whether male prostitution is an independent risk factor for HIV infection among male (intravenous and nonintravenous) drug users.

Design-a cross-sectional study.

Setting-various low-threshold methadone clinics and the sexually transmitted diseases clinic of the Municipal Health Service in Amsterdam and a drug-treatment centre in The Hague.

Participants-343 male intravenous drug users and 106 male non-intravenous drug users.
\end{abstract}

Main outcome measures-characteristics concerning drug use behaviour, sexual behaviour, and sociodemography, related to prostitution and HIV-antibodies.

Results - of the 449 study participants, 88 $(20 \%)$ reported a history of prostitution; no differences were found between intravenous and non-intravenous drug users. Younger age, West German nationality, and having had private homosexual sex contacts, were independent predictors of a history of prostitution. Independent predictors of HIV infection were (1) longer residency in Amsterdam; (2) having had predominantly homosexual private sex contacts; (3) longer duration of intravenous drug use; and (4) frequent needle sharing.

Conclusion-no evidence was found to suggest that male prostitution in itself contributed to the risk of HIV infection.

\section{Introduction}

Prostitution is an economic necessity for many drug users, both male and female. ${ }^{1}$ Of the estimated 20000 hard drug users living in The Netherlands, 7000 8000 reside in Amsterdam. ${ }^{2}$ Data on the prevalence of human immunodeficiency virus (HIV) infection among drug users in The Netherlands, overall, are

Municipal Health Service, Department of Public Health and Environment, Amsterdam

J A R van den Hoek, H J A van Haastrecht, $R$ A Coutinho scarce; however, studies have been conducted among drug users in Amsterdam, where approximately one third of the intravenous (IV) drug users have been found to be infected with HIV. ${ }^{1}$ Reports from social workers indicate that on an average day a minimum of 150 male prostitutes (mostly hard drug addicts) are soliciting in Amsterdam. This number fluctuates during the year, and its composition varies strongly. Since both prostitution and HIV infection are common among drug users, the question arises as to what extent prostitution has contributed to the acquisition of an HIV infection. An earlier study among drug addicted female prostitutes in Amsterdam showed that duration of prostitution was a risk factor for HIV infection, even after adjusting for the risk of IV drug use. ${ }^{3}$ This study was undertaken to determine if homosexual prostitution is an independent risk factor for HIV infection among male drug users.

\section{Methods}

In 1985 an epidemiological study of HIV infection among drug users was begun in Amsterdam. For this ongoing study (aspects of which have been previously described ${ }^{134}$ ), participants are recruited at various low-threshold methadone clinics and at the sexually transmitted diseases (STD) clinic which treats drug-using prostitutes. From September 1987 to January 1989 the study was extended to a drugtreatment centre in The Hague. In total 449 male and 360 female IV and non IV drug users were recruited from these clinics during December 1985 to March 1989. Only the 449 men were included in our study. Most (373) participants were enrolled into the study in Amsterdam, the remainder (76) in The Hague.

Participation in the study was voluntary. After informed consent had been obtained, specially trained nurses and physicians took blood samples and then interviewed participants by using a standard questionnaire that included questions concerning medical history (STD included), IV drug use, sexual preference, and history of prostitution. For our study, a drug user was defined as an IV drug user if he had ever injected drugs. Participants who had engaged in prostitution during the 6 months preceding study enrolment were considered current prostitutes, and were asked about various sex practices, the relative frequency of these practices, and the use of condoms in the past 6 months. Sexual preference with private sex contacts in the preceding 
5 years was recorded on a seven-point scale, which ranged from exclusively heterosexual to exclusively homosexual. Those having exclusively or almost exclusively homo-/heterosexual private sex contacts were considered predominantly homo-/heterosexual. Those with a less exclusive sexual preference were considered bisexual.

Enzyme-linked immunosorbent assays (ELISA) were used for HIV-antibody testing, and positive specimens were confirmed by immunoblotting and competitive ELISA. ${ }^{1}$

To test for association we used the chi square test for dichotomous variables, two-tailed $t$ tests for interval-scaled variables, and chi square test-fortrend for ordinal variables. Logistic regression analysis with maximum-likelihood estimation of model parameters ${ }^{5}$ was used to determine independent predictor variables for history of prostitution and for HIV infection. P-values of 0.05 or less were defined as significant.

\section{Results}

\section{General characteristics}

The mean age of the participants was 29.7 years (standard deviation (SD) 5.7 years). Most (82\%) men had Dutch nationality; $7 \%$ were West German, and $11 \%$ had other nationalities. Of the 449 study participants, 104 (23\%) were infected with HIV: 103 of these men had been enrolled in Amsterdam (103/ 373) and one in The Hague (1/76).

A history of IV drug use was reported by 343 $(76 \%)$ of all study participants. Of these $343,79 \%$ reported having injected drugs in the 6 months preceding study enrolment. Sixty per cent of these current drug users reported injecting heroin, in combination with cocaine; $19 \%$ injected heroin only,
$8 \%$ cocaine only, $5 \%$ amphetamine only and $8 \%$ injected other combinations.

Thirty men reported having had predominantly homosexual private sex contacts in the previous 5 years. A history of prostitution was reported by 88 men, 43 of whom reported having engaged in prostitution during the six months preceding study enrolment (current prostitution). No significant differences were seen between the participants in Amsterdam and those in The Hague with regard to the proportion reporting a history of prostitution (ever) or current prostitution (Amsterdam: $24 \%$ and $10 \%$, respectively; and The Hague: $19 \%$ and $9 \%$, respectively).

\section{Characteristics of current prostitutes}

Of the 43 men reporting current prostitution, 22 men reported working on the streets, 13 in bars/clubs, and seven at home or at their clients' homes (place of work was unknown for one man). The mean number of customers per month was 57 (SD 58), with a range from 1 to 270 . Regarding sex practices with clients, active masturbation was reported by $39 / 42$ men ( 1 unknown), orogenital contact by $35 / 42$ men, receptive anal contact by $23 / 42 \mathrm{men}$, and insertive anal contact by $20 / 42$ men. The proportions reporting "always using condoms" while practising the various sex practices were $28 \%(10 / 35)$ for orogenital contact, $56 \%(13 / 23)$ for receptive anal contact, and $45 \%$ $(9 / 20)$ for insertive anal contact.

Of those who practised receptive or insertive anal contact, $24 \%$ and $30 \%$, respectively reported having predominantly heterosexual private sex contacts, $44 \%$ and $50 \%$ respectively, bisexual private sex contacts, and $24 \%$ and $20 \%$ respectively, predominantly homosexual private sex contacts.

Table 1 Univariate analysis of human immunodeficiency virus (HIV) infection in 449 male hard-drug users, Amsterdam and The Hague

\begin{tabular}{|c|c|c|c|c|}
\hline \multirow[b]{2}{*}{ Variable } & \multicolumn{2}{|l|}{ HIV status } & \multirow[b]{2}{*}{$\begin{array}{l}\text { Odds } \\
\text { ratio }\end{array}$} & \multirow{2}{*}{$\begin{array}{l}95 \% \\
\text { Confidence } \\
\text { interval }\end{array}$} \\
\hline & $\begin{array}{l}\text { Seropositive } \\
n=104(\%) \dagger\end{array}$ & $\begin{array}{l}\text { Seronegative } \\
n=345(\%) \dagger\end{array}$ & & \\
\hline $\begin{array}{l}\text { Mean age ( } \pm \text { SD) } \\
\text { Non Dutch nationality } \\
\text { Amsterdam resident: }\end{array}$ & $\begin{array}{l}31 \cdot 0( \pm+4.9) \\
28(26 \cdot 9)\end{array}$ & $\begin{array}{l}29 \cdot 3( \pm 5 \cdot 9) \\
52(15 \cdot 1)\end{array}$ & ${ }^{\star} 2.08$ & $1 \cdot 23$ \\
\hline $\begin{array}{l}\text { Amsterdam resident: } \\
\text { No }\end{array}$ & $1(1.0)$ & $(22 \cdot 9)$ & 1 & \\
\hline $\begin{array}{l}<4 \text { years } \\
\geqslant 4 \text { years }\end{array}$ & $\begin{array}{ll}17 & (16 \cdot 3) \\
86 & (82 \cdot 7)\end{array}$ & $\begin{array}{r}87 \\
179 \\
175.25)\end{array}$ & $\begin{array}{l}15 \cdot 44 \\
37 \cdot 96\end{array}$ & $\begin{array}{l}2 \cdot 01-118 \cdot 68 \\
5 \cdot 19-277 \cdot 40\end{array}$ \\
\hline $\begin{array}{l}\text { IV drug user (ever) } \\
\text { Steady sex partner with drug-iniection history in preceding } 5 \text { vears }\end{array}$ & $99 \quad(95 \cdot 2)$ & $244 \quad(70 \cdot 7)$ & $\begin{array}{r}8 \cdot 20 \\
0 \cdot 86\end{array}$ & $3.24-20.73$ \\
\hline & $\begin{array}{ll}15 & (14 \cdot 6) \\
56 & (55 \cdot 4)\end{array}$ & $133(39.9)$ & $\begin{array}{l}0.86 \\
1.87\end{array}$ & $\begin{array}{ll}0.46- & 1.59 \\
1.19- & 2.93\end{array}$ \\
\hline $\begin{array}{l}\text { Predominantly homosexual (private) sex contacts } \\
\text { Male prostitution (ever) }\end{array}$ & $\begin{array}{ll}12 & (11 \cdot 7) \\
25 & (24 \cdot 0)\end{array}$ & $\begin{array}{ll}18 & (5 \cdot 2) \\
63 & (18 \cdot 3)\end{array}$ & $\begin{array}{l}2 \cdot 40 \\
1.42\end{array}$ & $\begin{array}{ll}1 \cdot 11-5 \cdot 16 \\
0.84-2 \cdot 40\end{array}$ \\
\hline $\begin{array}{l}\text { Receptive anal contact in previous } 6 \text { months with customers } \\
\text { History of: }\end{array}$ & $8(7.8)$ & $15(4 \cdot 4)$ & 1.84 & $0.76-\quad 4.47$ \\
\hline Syphilis & $11 \quad(10 \cdot 6)$ & $(4 \cdot 4)$ & 2.59 & $1.15-5.82$ \\
\hline Gonorrhoea & $31 \quad(29 \cdot 8)$ & $(23 \cdot 6)$ & $1 \cdot 37$ & $0.84-2.24$ \\
\hline Genital herpes & $(8 \cdot 7)$ & $(4.9)$ & 1.82 & $0 \cdot 79-\quad 4 \cdot 22$ \\
\hline
\end{tabular}

^Odds ratio not applicable; p-value: 0.004 .

†Because of missing values; some of the presented percentages are not based on the full number of seropositive or seronegative drug users. 
Table 2 Logistic regression analysis of human immunodeficiency virus ( HIV) infection in 429* male drug users.

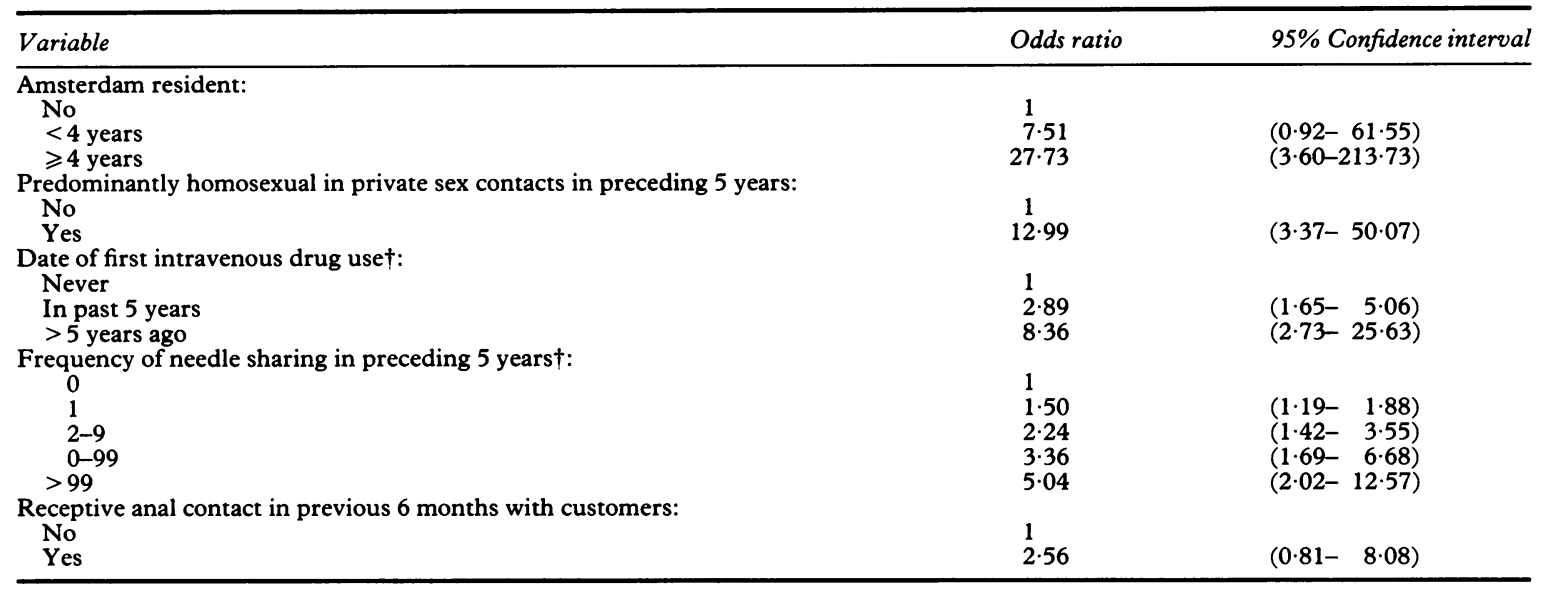

* Twenty participants had missing data on one or more of the predictor variables and were, therefore, excluded from this analysis.

$\dagger$ Modelled as a continuous variable.

\section{Comparison of characteristics of prostitutes and non-prostitutes}

Men reporting a history of prostitution differed from those who did not with respect to several characteristics: (1) they were younger $(26.9$ vs. 30.4 years; $\left.\mathrm{p}<10^{-6}\right)$; (2) they had lived in the town where they were enrolled for a shorter period of time $(47 \%$ vs. $25 \%$ were resident $<5$ years; $p=0.0001$ ); (3) they were more often of West German nationality $(15 \%$ vs. $5 \% ; p=0.002)$; and (4) they more frequently reported private homosexual contacts for the preceding 5 years $\left(68 \%\right.$ vs. $\left.10 \% ; \mathrm{p}<10^{-6}\right)$. In addition, men who had been prostitutes reported a history of STD (11\% vs. $4 \%$ had had syphilis in preceding 5 years; $p=0.01$ ) as well as a positive HIV-ab test result ( $28 \%$ vs. $22 \%$; p $=0 \cdot 19)$ more often than those who had not. A history of IV drug use (ever and current) was not reported significantly more often by the men who had engaged in prostitution than by the men who had not.

In determining independent predictors of a history of prostitution, sociodemographic information, drug-injection practices and sexual orientation were considered for inclusion into a logistic regression model. While having had private homosexual contacts in the past 5 years was clearly strongly related to a history of prostitution (odds ratio (OR) 19.7; 95\% confidence interval (CI) $10 \cdot 7-36 \cdot 4)$, both younger age (per year, OR $0.89 ; 95 \%$ CI $0.84-0.94$ ) and West German nationality (West German vs. other, OR 6.6; 95\% CI 2.6-17.2) also appeared to be significant independent predictors of prostitution.

\section{Univariate association between HIV seropositivity and variables}

Univariately significant associations were found between the presence of HIV antibody and the follow- ing characteristics: (1) mean age; (2) a non-Dutch nationality; (3) duration of residence in Amsterdam; (4) a history of IV drug use; (5) a predominantly homosexual preference in private sex contacts; and (6) a history of syphilis (table 1).

Neither a history of prostitution nor receptive anal intercourse with customers were significantly associated with HIV-Ab seropositivity, although both tended to be more common in HIV-infected participants.

\section{Logistic regression analysis}

Variables that were considered for inclusion as predictors of HIV infection into a logistic regression model were: (1) drug-injection variables (ever injected, when first injected, when last injected, frequency of needle sharing); (2) sociodemographic variables (nationality, age, duration of residency in Amsterdam); and (3) sexual behaviour variables (steady sex partner with drug-injection history, casual sex partner(s) with drug-injection history, homosexuality, history of prostitution, passive anal contact in past 6 months with customers, and history of syphilis). Variables that independently and significantly contributed to the fit of the model are shown in table 2 . Longer residency in Amsterdam, having had predominantly homosexual private sex contacts, longer duration of IV drug use, and frequent needle sharing were all found to be independently predictive of HIV infection. Since receptive anal contact with customers in the past 6 months was considered the best available variable indicating the risk of HIV infection through prostitution, it was included in the model regardless of significance. Its odds-ratio of 2.56 suggests some additional risk from this behaviour. All considered variables that were not included in the model would have had $p$ values $>0 \cdot 12$ associated 
with their contribution to the fit of the model, had they been included.

In a separate analysis (data not shown) it was shown that having had bisexual private sex contacts in the preceding 5 years did not involve more risk of being infected with HIV than having had predominantly heterosexual private sex contacts in this period (adjusted OR 0.87; 95\% CI 0.43-1·76).

\section{Discussion}

Our results show that prostitution is quite common among male drug users, with no significant differences between study participants in Amsterdam and those in The Hague nor between IV and non-intravenous drug users. However, male prostitution occurred much more frequently among participants who also reported having had homosexual contacts in private life.

No clear evidence was found that male prostitution in itself contributed to the risk for HIV infection among drug users, although the relative risk for receptive anal contact with customers suggested some additional risk from prostitution. However, the risk from receptive anal contacts with customers may also reflect the risk associated with engaging in this practice with private sex partners, a specific risk behaviour that was not measured separately and, therefore, could not be controlled for in multivariate analysis.

A homo-bisexual preference in private sex contacts was reported by $22 \%$ of the drug users with a history of IV drug use. This indicates a substantial overlap between male homosexuals and IV drug users. The first case of AIDS in The Netherlands was diagnosed in 1982 in a homosexual man and not until 1985 was AIDS diagnosed in an IV drug user. Information from both AIDS surveillance data and epidemiological studies ${ }^{6}$ indicate that HIV was probably introduced among homosexual men in The Netherlands at the end of the 1970s, and that the virus began circulating among IV drug users shortly thereafter. ${ }^{7}$ From the considerable overlap between these two groups, as shown in this study, the most plausible explanation is that HIV was introduced among drug users by male homosexuals.

Although prostitution, contrary to private homosexual contacts, does not seem to contribute significantly to the acquisition of HIV among male drug users, male prostitutes most likely continue to infect their clients. An ethnographic study of male prostitution in Glasgow showed that clients of male prostitutes often include large numbers of bisexual married men. ${ }^{8}$ In this way male prostitution could be a bridge for the spread of HIV among the general population.

Increased educational efforts for both male prostitutes and their clients are necessary since many may not consider themselves homosexuals and, therefore, do not recognise themselves as targets of prevention campaigns directed towards homosexual men.

We thank B Frölich, B Scheeringa-Troost, G Stienstra, J Teeuwissen and G H A de Haan for interviewing and collecting blood samples and $M$ ter Pelle for preparing the manuscript. This study was supported by a grant from the Netherlands Foundation for Preventive Medicine (grant 281258).

Address for correspondence: Mrs J A R van den Hoek, MD, PhD, Municipal Health Service, Department of Public Health and Environment, F.O. Box 20244, 1000 HE Amsterdam, The Netherlands.

1 Van den Hoek JAR, Coutinho RA, Van Haastrecht HJA, Van Zadelhoff AW, Goudsmit J. Prevalence and risk factors of HIV infections among drug users and drug using prostitutes in Amsterdam. AIDS 1988;2:55-60.

2 Buning EC, Coutinho RA, Van Brussel G, Van Santen G, Van Zadelhoff A. Preventing AIDS in drug addicts in Amsterdam (letter). Lancet 1986;ii:1435.

3 Van den Hoek JAR, Van Haastrecht HJA, Scheeringa-Troost B, Goudsmit J, Coutinho RA. HIV infection and STD in drug addicted prostitutes in Amsterdam: potential for heterosexual HIV transmission. Genitourin Med 1989;65:146-50.

4 Van den Hoek JAR, Van Haastrecht HJA, Coutinho RA. Risk reduction among intravenous drug users in Amsterdam under the influence of AIDS. Am J Public Health 1989;79:1355-7.

5 Dixon WJ (ed.). BMDP Statistical Software Manual. Berkeley: University of California Press, 1988.

6 Coutinho RA, Bos JM, Ruitenberg EJ. The epidemiology of LAV/HTLV-III infection in Europe. In: Staquet $M$, Hemmer K, Baert A, eds. Clinical Aspects of AIDS and AIDS-related Complex. Oxford: Oxford University Press, 1986:7-14.

7 Coutinho RA, Krone WJA, Smit L, et al. The introduction of LAV/HTLV-III into the male homosexual community in Amsterdam. Genitourin Med 1986;62:38-43.

8 Bloor M, McKeganey N, Barnard M. An ethnographic study of HIV related risk practices among Glasgow rent boys and their clients: report of a pilot study. AIDS Care 1990;2:17-24.

Accepted for publication 14 May 1991 